\title{
Alterations in triad ultrastructure following repetitive stimulation and intracellular changes associated with exercise in amphibian skeletal muscle
}

\author{
Juliet A. Usher-Smith · James A. Fraser • \\ Christopher L.-H. Huang · Jeremy N. Skepper
}

Received: 24 August 2006/ Accepted: 5 January 2007/Published online: 2 March 2007

(C) Springer Science+Business Media B.V. 2007

\begin{abstract}
This study used Rana temporaria sartorius muscles to examine the effect of fatiguing electrical stimulation on the gap between the T-tubular and sarcoplasmic reticular membranes (T-SR distance) and the T-tubule diameter and compared this with corresponding effects on resting fibres exposed to a range of extracellular conditions that each replicate one of the major changes associated with muscular activity: membrane depolarisation, isotonic volume increase, acidification and intracellular lactate accumulation. Following each treatment, muscles were immersed in isotonic fixative solution and processed for transmission electron microscopy (TEM). Mean T-SR distances were estimated from orthogonal intercepts to provide estimates of diffusion distances between $\mathrm{T}$ and $\mathrm{SR}$ membranes and T-tubule diameter was estimated by measuring its shortest axis in the sampled J-SR complexes. Measurements from muscles fatigued by low frequency intermittent stimulation showed significant $(P<<0.05)$ reversible increases in both T-SR distance and T-tubule diameter from $15.97 \pm 0.37 \mathrm{~nm}$ to $20.15 \pm$ $0.56 \mathrm{~nm}$ and from $15.44 \pm 0.60 \mathrm{~nm}$ to $22.26 \pm 0.84 \mathrm{~nm}$ $(n=40,30)$ respectively. Exposure to increasing concentrations of extracellular $\left[\mathrm{K}^{+}\right]$in the absence of $\mathrm{Cl}^{-}$to produce membrane depolarisation without
\end{abstract}

\section{J. A. Usher-Smith $(\bowtie) \cdot$ J. A. Fraser .}

C. L.-H.Huang

Physiological Laboratory, Department of Physiology,

Development and Neuroscience, University of Cambridge,

Downing Street, Cambridge CB2 3EG, UK

e-mail: jau20@cam.ac.uk

J. N. Skepper

Multi-Imaging Centre, University of Cambridge, Cambridge CB2 3DY, UK accompanying cell swelling reduced T-SR distance and increased T-tubule diameter, whilst comparable increases in $\left[\mathrm{K}^{+}\right]_{\mathrm{e}}$ in the presence of $\mathrm{Cl}^{-}$suggested that isotonic cell swelling has the opposite effect. Acidification alone, produced by $\mathrm{NH}_{4} \mathrm{Cl}$ addition and withdrawal, also decreased T-SR distance and T-tubule diameter. A similar reduction in T-SR distance occurred following exposure to extracellular Na-lactate where such acidification was accompanied by elevations of intracellular lactate, but these conditions produced a significant swelling of T-tubules attributable to movement of lactate from the cell into the T-tubules. This study thus confirms previous reports of significant increases in T-SR distance and T-tubule diameter following stimulation. However, of membrane depolarisation, isotonic cell swelling, intracellular acidification and lactate accumulation, only isotonic cell swelling increases T-SR distance whilst membrane depolarisation and intracellular lactate likely contribute to the observed increases in T-tubule diameter.

Keywords Skeletal muscle $\cdot$ Stimulation $\cdot$ Triad ultrastructure

\section{Introduction}

Exercise is associated with transmembrane movements of water and an accompanying cell swelling in both in vivo and in vitro skeletal muscle preparations (Blinks 1965; Lannergren 1990; Rapp et al. 1998; Sjogaard 1983; Sjogaard et al. 1985). A limited degree of cell swelling might enhance muscle function: decreases in intracellular ionic strength accompanying increases in cell volume may directly increase force 
generated per actin-myosin crossbridge (Bressler and Matsuba 1991; Rapp et al. 1998). However, osmotically-induced changes in cell volume have been reported to alter myocyte ultrastructure, particularly of the transverse (T-) tubules and sarcoplasmic reticulum (SR) and the geometrical relationship between them at the triad junctions (Franzini-Armstrong and Nunzi 1983; Freygang et al. 1967; Martin et al. 2003; Rapoport et al. 1969). This may have potential functional significance for the coupling of tubular voltage sensing to the release of intracellularly stored $\mathrm{Ca}^{2+}$ in muscle activation which likely involves reciprocal allosteric interactions between groupings of tubular dihydropyridine receptors (DHPRs) acting as voltage sensors (Franzini-Armstrong and Protasi 1997; Huang 1993) and quatrefoil SR ryanodine receptor (RyR) acting as $\mathrm{Ca}^{2+}$ release channels (Franzini-Armstrong and Protasi 1997; Huang 1993; Huang 1998; Nakai et al. 1996). Such highly stereospecific interactions could well be sensitive to micro-anatomical disruptions in either T-tubular geometry or T-SR membrane spacing and alterations described previously following exposure to extracellular hypotonicity have indeed been associated with altered $\mathrm{Ca}^{2+}$ release properties in quiescent fibres (Chawla et al. 2001; Martin et al. 2003) and reduced transverse-tubule charge movement (Bruton et al. 2000). A series of recent papers (Lamb et al. 1995; Verburg et al. 2005, 2006) have also shown that increases in the cytoplasmic $\left[\mathrm{Ca}^{2+}\right]$ of the kind observed during electrical stimulation in $\mathrm{Ca}^{2+}$-containing solutions cause an irreversible reduction in the depolarisation-induced force response by interrupting excitation-contraction $(\mathrm{E}-\mathrm{C})$ coupling and this uncoupling is associated with T-tubule swelling (to 2-5 times tubular diameter observed in control fibres) and a significantly greater $(P<0.05)$ distance across each triad $(477 \pm 24 \mathrm{~nm}, n=38$ compared to $343 \pm 10 \mathrm{~nm}, n=37$ in controls) (Lamb et al. 1995).

Many electrophysiological studies additionally implicate E-C coupling as a potential candidate for the site of failure during fatigue: action potentials appear to propagate normally into the T-tubules (Lannergren and Westerblad 1987; Westerblad and Lannergren 1986) but this is accompanied by a reduced capacity to produce spatially homogenous calcium transients which can be overcome by using caffeine, whose action bypasses the E-C coupling mechanisms (Allen et al. 1989).

Since the suggestion that swelling of the T-tubules might play a role in fatigue was first made in 1978 (Somlyo et al. 1978), several studies have explored structural changes which might account for the E-C uncoupling but these have variously shown either no effect or increases in T-tubule diameter (Eisenberg and Gilai 1979; Gonzalez-Serratos et al. 1978; Lannergren et al. 1990). This study used established electron microscopic methods and a standardised stimulation protocol to directly demonstrate that repetitive stimulation is indeed accompanied by disruptions in the triad structure with significant increases in both T-SR distances and T-tubular diameter. These changes were then compared with those resulting from exposure of resting muscles to a range of extracellular conditions designed to replicate one or more of the major changes associated with muscular activity. Where possible, these changes were replicated individually but where this was not easily achievable, the respective effects were separated in experiments that involved paired conditions. This made it possible to establish the relative contributions of membrane depolarisation (Juel 1986, 1988; Lindinger and Sjogaard 1991; Westerblad and Lannergren 1986), isosmotic cell swelling (Lannergren 1990; Rapp et al. 1998; Sjogaard 1983; Sjogaard et al. 1985), decreased intracellular $\mathrm{pH}$ (Krause and Wegener 1996; Sullivan et al. 1994) and intracellular lactate accumulation (Bangsbo et al. 1990; Sjoholm et al. 1983) to the observed alterations in myocyte ultrastructure during exercise.

\section{Methods}

All experiments used sartorius muscles from coldadapted winter frogs, Rana temporaria, (Blades Biological, UK) killed by concussion followed by pithing (Schedule 1: Animal Procedures Act, Home Office, UK). Experiments were conducted at $22^{\circ} \mathrm{C}$. The solutions used were based on either normal Ringer solution (mM: $115 \mathrm{NaCl}, 2.5 \mathrm{KCl}, 1.8 \mathrm{CaCl}_{2}, 3.0$ HEPES) or chloride $\left(\mathrm{Cl}^{-}\right)$-free, sulphate $\left(\mathrm{SO}_{4}^{2-}\right)$ Ringer solution (75 Na $\mathrm{Na}_{2} \mathrm{SO}_{4}, 1.25 \quad \mathrm{~K}_{2} \mathrm{SO}_{4}, 8 \mathrm{CaSO}_{4}, 3.0$ HEPES). All solutions were titrated to $\mathrm{pH} 7$ (measured with a Philips Combination $\mathrm{pH}$ Electrode, standardised at $\mathrm{pH} 7$ in phosphate buffer) using $1 \mathrm{M}$ $\mathrm{NaOH}$ and $1 \mathrm{M} \mathrm{HCl}$ and their osmolarity measured using a standard, calibrated vapour pressure osmometer (Wescor, UK). $\mathrm{KCl}, \mathrm{K}_{2} \mathrm{SO}_{4}, \mathrm{Na}-(\mathrm{L})$ Lactate and $\mathrm{NH}_{4} \mathrm{Cl}$ replaced equimolar amounts of $\mathrm{NaCl}$ or $\mathrm{Na}_{2} \mathrm{SO}_{4}$ to give isosmotic solutions containing 15 or $60 \mathrm{mM} \mathrm{K}^{+}, 80 \mathrm{mM}$ lactate and $40 \mathrm{mM} \mathrm{NH}_{4} \mathrm{Cl}$.

For all experiments conducted under conditions of $\mathrm{Cl}^{-}$deprivation, the muscle was gradually equilibrated with $\mathrm{Cl}^{-}$-free solutions by successively halving the $\mathrm{Cl}^{-}$ content of the bathing solution approximately every 5 min before its final transfer from $1 \mathrm{mM} \mathrm{Cl}^{-}$-Ringer to $\mathrm{Cl}^{-}$-free Ringer. 
In fatigue experiments, the muscle was stimulated directly by applying a voltage across two platinum electrodes in contact with the bath using a constant voltage isolated stimulator linked to a train/delay generator (Digitimer, Welwyn Garden City, UK). Muscles were exposed to 80 sets of stimulation where each set consisted of a $2 \mathrm{~s}$ stimulus given at intervals of $8 \mathrm{~s}$ with impulses $20 \mathrm{~ms}$ long at $20 \mathrm{~V}$ used at a frequency of $25 \mathrm{~Hz}$ (Usher-Smith et al. 2006a, b). Measurements of peak twitch tension recorded during individual $10 \mathrm{~V}$ (field strength $\sim 1 \mathrm{~V} / \mathrm{cm}$ ) stimuli $20 \mathrm{~ms}$ long using an isometric force transducer (Model 2 Number 724,485, Harvard Apparatus, USA) connected to a Model 1401 analogue to digital converter (Cambridge Electronic Design, Cambridge, UK) linked to a computer running Spike 2 version 3.19 for windows (Cambridge Electronic Design, UK) showed that this protocol reduces tetanic force to $25.7 \pm 0.7 \%(n=3)$ of its initial value.

Following each individual experimental protocol, sartorius muscles were fixed by immersion in a standardised fixative solution: 0.05 M PIPES buffer corrected to $\mathrm{pH} 7.4$ with $\mathrm{NaOH}$ to give a final $\left[\mathrm{Na}^{+}\right]$ of $80 \mathrm{mM}, 3 \%$ glutaraldehyde and $2 \mathrm{mM} \mathrm{CaCl}_{2}$ with $\mathrm{H}_{2} \mathrm{O}_{2}(33 \% ; 100 \mu \mathrm{l} / 10 \mathrm{ml})$ added to the fixative as an oxygen donor to speed up the process of fixation, making it more efficient and homogeneous (Peracchia and Mittler 1972). This was chosen so that any resulting alteration in tissue anatomy resulting from the fixation stage would be as consistent as possible across the different conditions and permit comparison between them. This would not have been possible if the fixation conditions had been varied through the different physiological testing conditions. The muscles were then osmicated, bulk stained and embedded in Spurr's resin. Thin sections $(50 \mathrm{~nm})$ of longitudinally orientated fibres were mounted on copper grids and stained with uranyl acetate and lead citrate and viewed in a Philips CM100 operated at $80 \mathrm{kV}$. The mean distance between the junctional SR (J-SR) and the T-system was then estimated. Ten muscle fibres were randomly sampled and 10 T-SR junctions were subsampled from each. At a magnification of $160,000 \times$ a vertical linear test system was overlain and T-SR junctions intersecting with the test system were selected when a test line intersected either the $\mathrm{T}$ or the SR component of a junction (Fig. 1). The length of an orthogonal intercept was then measured between the $\mathrm{T}$ and the $\mathrm{SR}$ at such sites and expressed as the mean of the ten measurements. T-tubule diameter was estimated by measuring its shortest axis in the sampled J-SR complexes.

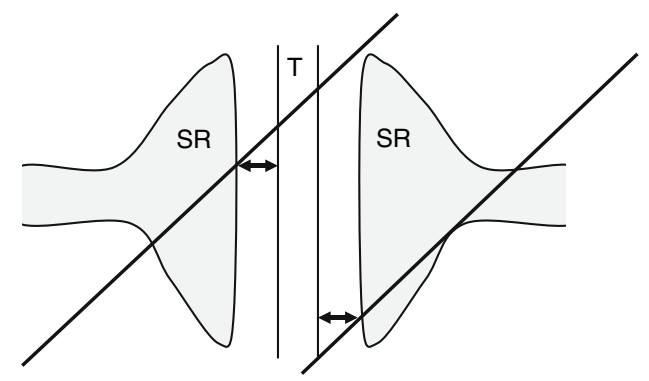

Fig. 1 Schematic diagram illustrating the orthogonal method of measurement of the T-SR distance. A linear test system was overlain and, where a test line intersected either the T-tubular (T) or sarcoplasmic reticular (SR) component of a junction, the length of an orthogonal intercept $(\leftrightarrow)$ was measured between the $\mathrm{T}$ and SR

\section{Results}

Effects of repetitive stimulation

Initial experiments investigated the effect of a repetitive stimulation protocol on the morphology of triad junctions in the superficial fibres of amphibian fast twitch skeletal muscle. Figure 2 shows typical images from representative sections of control sartorius muscles (a), muscles first exposed to 80 sets of electrical field stimulation (b) and muscles exposed to 80 sets of electrical field stimulation but then allowed to recover in normal Ringer solution for $60 \mathrm{~min}$ before fixation (c). Quantitative measurements from these muscles showed a profound, but reversible, disruption of triad anatomy following stimulation (Fig. 3) with statistically significant $(P<<0.05)$ increases in both T-SR distances and T-tubular diameters (from $15.97 \pm 0.37 \mathrm{~nm}$ to $20.15 \pm 0.56 \mathrm{~nm}$ and from $15.44 \pm 0.60 \mathrm{~nm}$ to $22.26 \pm 0.84 \mathrm{~nm}$; means $\pm \mathrm{SEM} ; n=40$ and 30 fibres for control and stimulated muscles respectively). The subsequent experiments then compared these changes with those resulting from exposure of resting muscles to four different extracellular conditions that each sought to replicate one or more of the major changes known to be associated with muscular activity.

Effects of membrane depolarisation

The first cellular change investigated was membrane depolarisation. Sustained activity is known to depolarise the membrane potential, $E_{\mathrm{m}}$, to values positive to -60 mV (Juel 1986; Lindinger and Sjogaard 1991; Westerblad and Lannergren 1986) as a result of the influx of $\mathrm{Na}^{+}$and efflux of $\mathrm{K}^{+}$associated with each action potential. Such depolarisation can be reproduced in resting muscle by exposure to increased 

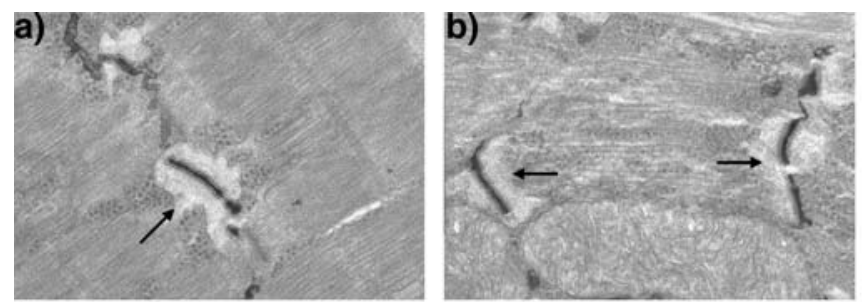

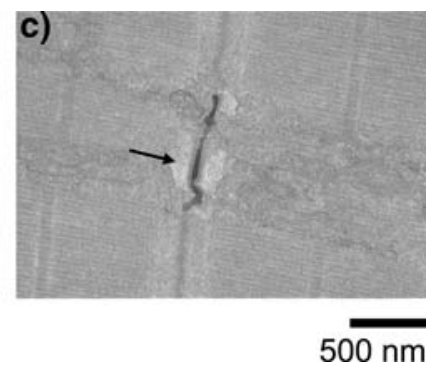

exposed to electrical stimulation but then allowed to recover in normal Ringer solution for $60 \mathrm{~min}$
Fig. 2 Representative transmission electron microscopy images of triads (arrows) in (a) control muscles, (b) muscles exposed to intermittent low frequency electrical stimulation and (c) muscles

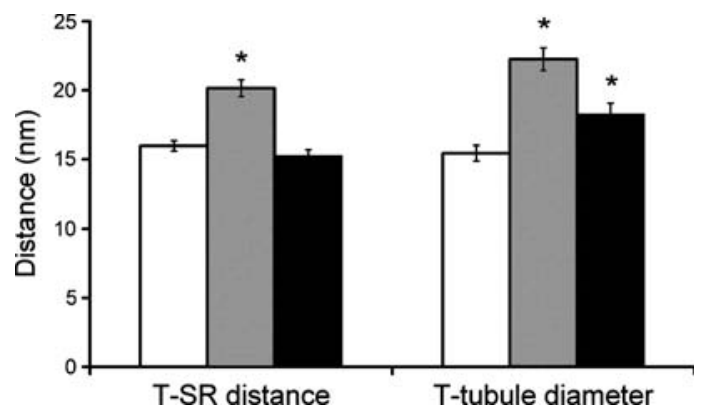

Fig. 3 Measurements (means $\pm \operatorname{SEM} ; n=3$ ) of T-SR distance and T-tubule diameter from serial EM sections of control muscles (blank bars), muscles exposed to intermittent low frequency electrical stimulation (grey bars) and muscles exposed to electrical stimulation but then allowed to recover in normal Ringer solution for $60 \mathrm{~min}$ (black bars). *indicates a significant $(P<0.05)$ difference from control muscles

concentrations of extracellular $\mathrm{K}^{+}$(Adrian 1956). The high permeability to $\mathrm{Cl}^{-}$relative to that of $\mathrm{K}^{+}$in amphibian skeletal muscle, however, then results in an accompanying $\mathrm{Cl}^{-}$entry which in turn increases the total intracellular solute content and drives water entry and an increase in cell volume (Boyle and Conway 1941; Usher-Smith et al. 2006b). This volume change can be prevented by replacing the extracellular $\mathrm{Cl}^{-}$ with $\mathrm{SO}_{4}^{2-}$ to abolish $\mathrm{Cl}^{-}$fluxes. Accordingly, muscles previously equilibrated with chloride-free solutions were first exposed for $60 \mathrm{~min}$ to extracellular chloridefree solutions containing either 15 or $60 \mathrm{mM}\left[\mathrm{K}^{+}\right]_{\mathrm{e}}$ to investigate the effect of membrane depolarisation alone on the triad ultrastructure. The $\mathrm{K}^{+}$concentration of $15 \mathrm{mM}$ was chosen as it produces a depolarisation similar to that seen after stimulation $(35.3 \pm 0.76 \mathrm{mV}$ $(n=3)$ and $23.6 \pm 0.98 \mathrm{mV}(n=3)$ respectively, Usher-Smith et al. 2006b) and that of $60 \mathrm{mM}$ to maximise any possible effects on the triad ultrastructure. Figure $4 \mathrm{a}$ shows that both concentrations result in significant $(P<<0.05, n=\sim 30)$ decreases in T-SR distance, with $60 \mathrm{mM}$ having a significantly $(P<<0.05$, $n=\sim 30)$ greater effect than $15 \mathrm{mM}$. In contrast, $15 \mathrm{mM} \quad \mathrm{K}_{2} \mathrm{SO}_{4}$ caused only a small insignificant $(P=0.69)$ increase in T-tubule diameter whilst exposure to $60 \mathrm{mM} \mathrm{K}_{2} \mathrm{SO}_{4}$ results in significant swelling to $35.50 \pm 1.11 \mathrm{~nm}(n=20)$.

Combined effects of membrane depolarisation and isosmotic cell swelling

The second cellular change explored was the isosmotic cell swelling known to accompany muscular activity (Lannergren 1990; Rapp et al. 1998; Sjogaard 1983; Sjogaard et al. 1985). It is not possible to reproduce such isosmotic increases in cell volume in skeletal muscle in the absence of changes in the membrane potential. However, the above experiments in $\mathrm{SO}_{4}^{2-}$ containing solutions demonstrated the effects of membrane depolarisation alone and showed that there is no significant difference in T-SR distance and only a small increase in T-tubule diameter between control muscles in normal Ringer solution and $\mathrm{Cl}^{-}$-free Ringer solution $(15.97 \pm 0.37$ and $15.44 \pm 0.46$, and $17.41 \pm$ 0.68 and $17.99 \pm 1.13 \mathrm{~nm}$ for T-SR distance and T-tubule diameter in $\mathrm{Cl}^{-}$containing and $\mathrm{Cl}^{-}$free Ringer solution respectively; $P=0.08$ and 0.05 ). This slight T-tubule swelling is consistent with previous reports of increases in T-tubule volume in amphibian fibres in $\mathrm{Cl}^{-}$-free sulphate solutions (Dulhunty 1982) and in low $(30 \mathrm{mM}) \mathrm{Cl}^{-}$solutions (Freygang et al. 1964). Repeating these increases in extracellular $\mathrm{K}^{+}$ concentration, $\left[\mathrm{K}^{+}\right]_{\mathrm{e}}$, in the presence of a normal extracellular $\mathrm{Cl}^{-}$thus allows the combined effects of the membrane depolarisation and cell swelling to be observed (Fig. 4b). Under these conditions, there was no significant $(P=0.29)$ change in T-SR distance in the presence of $15 \mathrm{mM}\left[\mathrm{K}^{+}\right]_{\mathrm{e}}$ (hashed bars) whilst $60 \mathrm{mM}$ $\left[\mathrm{K}^{+}\right]_{\mathrm{e}}$ (solid bars) resulted in a significant reduction in this distance. In contrast, $15 \mathrm{mM}\left[\mathrm{K}^{+}\right]_{\mathrm{e}}$ resulted in a small $(1.8 \mathrm{~nm})$ decrease in T-tubule diameter 


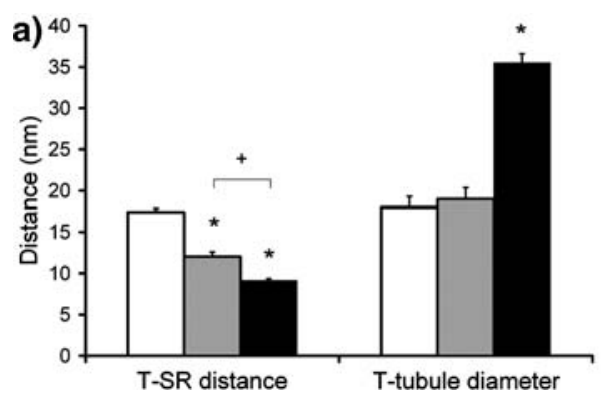

Fig. 4 (a) Shows the effects of $15 \mathrm{mM}$ (grey bars) and $60 \mathrm{mM}$ (black bars) extracellular $\left[\mathrm{K}^{+}\right]$in $\mathrm{Cl}^{-}$-free $\mathrm{SO}_{4}^{2-}$ containing Ringer solution on T-SR distance and T-tubule diameter (mean$\mathrm{s} \pm \mathrm{SEM}$ ) compared to normal $\mathrm{Cl}^{-}$-free $\mathrm{SO}_{4}^{2-}$ Ringer solution (open bars). (b) Shows the corresponding effects of $15 \mathrm{mM}$ (grey

$(P=0.01)$ and $60 \mathrm{mM}\left[\mathrm{K}^{+}\right]_{\mathrm{e}}$ produced a significant increase in T-tubule diameter. Comparing these findings to the effects of depolarisation alone (Fig. 4a) suggests that the additional effect of isosmotic cell swelling is to produce an increase in T-SR distance and decrease in T-tubule diameter: the T-tubule diameter after exposure to both 15 and $60 \mathrm{mM}\left[\mathrm{K}^{+}\right]_{\mathrm{e}}$ in the presence of $\mathrm{Cl}^{-}$was less than that observed in $\mathrm{SO}_{4}^{2-}$ solutions and in $15 \mathrm{mM}\left[\mathrm{K}^{+}\right]_{\mathrm{e}}$ the effect of the accompanying isosmotic cell swelling in the presence of $\mathrm{Cl}^{-}$was able to offset the decrease in T-SR distance seen in $\mathrm{SO}_{4}^{2-}$ solutions. This effect on T-SR distance was still seen at $60 \mathrm{mM}\left[\mathrm{K}^{+}\right]_{e}$, however, here the net effect of depolarisation and isosmotic cell swelling was still to produce a net decrease in T-SR distance.

\section{Effects of intracellular acidification}

The third intracellular change investigated was the decrease in intracellular $\mathrm{pH}$ accompanying muscular activity (Krause and Wegener 1996; Sullivan et al. 1994). Intracellular acidification in the presence of a constant extracellular $\mathrm{pH}$ was achieved using a standard experimental protocol of $\mathrm{NH}_{4} \mathrm{Cl}$ addition and subsequent withdrawal (Boron and De Weer 1976; Putnam et al. 1986; Vaughan-Jones and Wu 1990). Prior to fixation muscles were exposed to a solution containing $40 \mathrm{mM} \mathrm{NH} \mathrm{NH}_{4} \mathrm{Cl}$ for $100 \mathrm{~min}$ and then returned to normal Ringer for a further $40 \mathrm{~min}$ as this has been shown to result in a fall in intracellular $\mathrm{pH}$ of $0.53 \pm 0.10 \mathrm{pH}$ units in this amphibian preparation without changes in membrane potential (Fraser et al. 2005). Previous microelectrode measurements of intracellular $\mathrm{pH}$ have shown the resting $\mathrm{pH}_{\mathrm{i}}$ of frog sartorii to be $7.27 \pm 0.01 \mathrm{pH}$ units $(n=75$ fibres, 11 muscles) (Usher-Smith et al. 2006a). The protocol adopted here therefore results in a final $\mathrm{pH}_{\mathrm{i}}$ of approximately $6.74 \pm 0.10$ units which is close to the

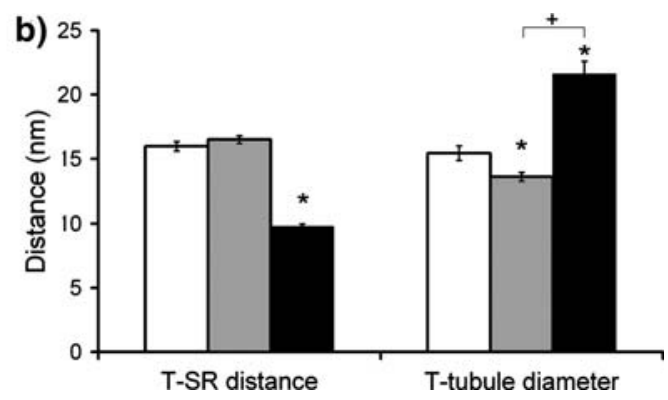

bars) and $60 \mathrm{mM}$ (black bars) extracellular $\left[\mathrm{K}^{+}\right]$in $\mathrm{Cl}^{-}$containing Ringer solution compared to normal Ringer solution (open bars). *Indicates a significant $(P<0.05)$ difference from control muscles and ${ }^{+}$a significant difference between two conditions

range 6.30-6.70 recorded in fatigued frog sartorius surface fibres following electrical stimulation (Renaud et al. 1986). Any changes observed in the ultrastructure in these resting fibres therefore replicate those arising as a result of changes in $\mathrm{pH}_{\mathrm{i}}$ following stimulation. Figure 5 shows that such acidification (grey bars) causes a significant decrease in both T-SR distance and T-tubule diameter to $9.99 \pm 0.2 \mathrm{~nm}(n=30)$ and $13.55 \pm 0.2 \mathrm{~nm}(n=30)$ respectively when compared with controls (clear bars).

\section{Combined effects of intracellular acidification} and lactate accumulation

The final change investigated was an increase in intracellular lactate which can reach $\sim 30 \mathrm{mM}$ in human fast-twitch skeletal muscle fibres with anaerobic exercise (Bangsbo et al. 1990; Sjoholm et al. 1983). As with the isosmotic cell volume increase, it is not possible to replicate this increase in lactate by itself in vitro as most lactate introduced into the extracellular space

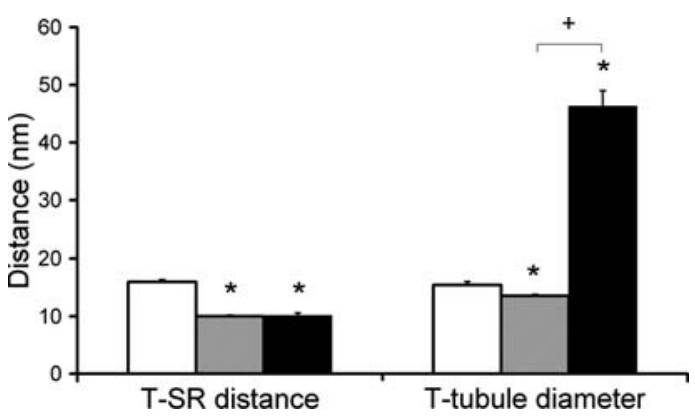

Fig. 5 The effects of intracellular acidification brought about by addition and withdrawal of $\mathrm{NH}_{4} \mathrm{Cl}$ (grey bars) and exposure to extracellular lactate (black bars) on T-SR distance and T-tubule diameter compared to normal Ringer solution (open bars). *Indicates a significant $(P<0.05)$ difference from control muscles and ${ }^{+}$a significant difference between two conditions 
enters cells in association with $\mathrm{H}^{+}$ions, with $<1 \%$ of the total flux due to entry of the lactate ${ }^{-}$anion alone (Mason and Thomas 1988). However, we have recently shown that exposure of frog sartorius muscles to isosmotic extracellular solutions containing $80 \mathrm{mM}$ lactate for $40 \mathrm{~min}$ results in an intracellular lactate concentration comparable with that observed after the stimulation protocol employed in this study together with an intracellular $\mathrm{pH}$ within the range previously reported for fatigued frog muscle (Usher-Smith et al. 2006a) in the absence of any change in membrane potential. Under such conditions (Fig. 5, filled bars) there was a significant decrease in T-SR distance, which was indistinguishable $(P=0.79, n=30)$ from that resulting from acidification alone, and a trebling of T-tubule diameter to $46.30 \pm 2.7 \mathrm{~nm}$.

\section{Discussion}

The present study used transmission electron microscopy (TEM) to investigate the influence of electrical stimulation and a range of intracellular changes associated with fatigue on the structure of the triads in amphibian skeletal muscle. All studies that involve electron microscopy necessarily involve a fixing of the tissue and a consequent deviation of tissue structure from its normal anatomy under the physiological conditions that immediately precede the fixation stage. However, consistent use of the same fixation procedures permit a comparison between the results of exposing muscles to different physiological conditions prior to fixation. Accordingly, the present study adopted consistent fixation procedures not only to muscle fibres exposed to the varied physiological manoeuvres but also to the controls so that any variations between the results would be the result of these prior physiological manoeuvres and not varying fixation procedures. TEM has previously been used to provide quantitative estimates of the gap between the T-tubular and the SR membranes, the T-SR distance, and the T-tubule diameter (Martin et al. 2003).

The first series of experiments demonstrated significant, reversible, increases in both T-SR distance and T-tubule diameter following intermittent low frequency electrical stimulation. These changes in T-tubule diameter are consistent with previous reports of T-tubule swelling in amphibian muscle following electrical stimulation (Eisenberg and Gilai 1979; Gonzalez-Serratos et al. 1978) and fast twitch rat muscle fibres following both chronic low-frequency stimulation (Frias et al. 2004) and downhill running (Takekura et al. 2001). To our knowledge, however, this the first report of increases in T-SR distance following fatigue. Nevertheless, earlier studies have observed E-C coupling failure in injured muscle fibres (Balnave and Allen 1995; Ingalls et al. 1998; Warren et al. 1993) and shown that intermittent electrical stimulation to fatigue causes reductions in the caffeine sensitivity of SR $\mathrm{Ca}^{2+}$ release and decreases depolarisation-induced release across a range of cholinechloride concentrations (Williams 2004). Bruton et al. (2000) also showed reduced transverse-tubule charge movement in fatigued fibres subsequently exposed to a hypotonic solution, consistent with a model where fatigue alters the coupling between the voltage sensors and calcium channels of the SR (Bruton et al. 2000).

Given that this coupling likely involves reciprocal allosteric interactions between the tubular DHPRs (Franzini-Armstrong and Protasi 1997; Huang 1993) and SR RyRs (Franzini-Armstrong and Protasi 1997; Huang 1993; Huang 1998; Nakai et al. 1996) it is not unreasonable that it could be sensitive to such microanatomical disruptions in either T-tubular geometry or T-SR membrane spacing and thus that the above changes would influence muscle function. It is not clear, however, whether these changes are a direct result of disruption of myofibrils associated with contraction, or whether they are due to cellular changes accompanying repeated activity. Accordingly, this study used a series of paired manoeuvres to explore the effects of other cellular changes on the triad ultrastructure.

The effect of membrane potential was investigated by exposing muscles to solutions containing increased $\left[\mathrm{K}^{+}\right]_{\mathrm{e}}$ in $\mathrm{Cl}^{-}$free solutions for $60 \mathrm{~min}$ prior to fixation to produce prolonged membrane depolarisation whilst avoiding the accompanying cell swelling (Usher-Smith et al. 2006b). Comparing these muscles to controls showed that such prior depolarisation alone empirically decreases T-SR distance and increases T-tubule diameter. The latter finding is in contrast to that reported by Launikonis and Stephenson (2002) where increasing $\left[\mathrm{K}^{+}\right]_{\mathrm{e}}$ whilst maintaining a constant $\left[\mathrm{K}^{+}\right]\left[\mathrm{Cl}^{-}\right]$product produced a reduction in T-tubule diameter (Launikonis and Stephenson 2002). It is possible that the differences observed are related to differences in exposure time to depolarising solutions although it is not clear from that study how long muscles were exposed to solutions with raised $\left[\mathrm{K}^{+}\right]_{\mathrm{e}}$. An explanation to account for the swelling seen with prolonged depolarisation in the present study could be that as the cell depolarises there will be $\mathrm{K}^{+}$leakage out of the cell and $\mathrm{Na}^{+}$entry which will increase the $\mathrm{Na}^{+} /$ $\mathrm{K}^{+}$pump activity. As there is a high density of $\mathrm{Na}^{+} / \mathrm{K}^{+}$ pumps in the T-tubule membrane this in turn will result 
in a net increase in cation concentration within the T-tubules which will draw in water and cause T-tubule swelling.

Repeating these increases in $\left[\mathrm{K}^{+}\right]_{\mathrm{e}}$ in the presence of a normal extracellular $\left[\mathrm{Cl}^{-}\right]$then allowed the combined effects of membrane depolarisation and isotonic cell swelling to be observed. These changes were considered together as under isotonic conditions skeletal muscle cell swelling requires the entry of $\mathrm{Cl}^{-}$and this in turn requires either depolarisation of the cell membrane to alter the passive $\mathrm{Cl}^{-}$distribution across the cell membrane and drive $\mathrm{Cl}^{-}$into the cell, or activation of cation-chloride co-transporters (Fraser and Huang 2004). The latter, however, would also cause significant depolarisation by raising intracellular chloride such that its equilibrium potential would be positive to the original resting potential and thus, because of the high $\mathrm{Cl}^{-}$permeability of skeletal muscle, depolarising the cell (Vaughan-Jones 1982).

Comparing the changes in T-SR distance under $\mathrm{Cl}^{-}$free conditions, where prior exposure to high $\left[\mathrm{K}^{+}\right]_{\mathrm{e}}$ caused decreased T-SR distance, with the results following an identical fixation protocol of muscles first exposed to high $\left[\mathrm{K}^{+}\right]_{\mathrm{e}}$ in the presence of $\mathrm{Cl}^{-}$which results in both membrane depolarisation and cell swelling, showed that the additional effect of isotonic cell swelling was to increase T-SR distance. This was most obvious with $15 \mathrm{mM}\left[\mathrm{K}^{+}\right]_{\mathrm{e}}$ where the additional effect of isotonic cell swelling precisely offset the reduction in T-SR distance seen with depolarisation alone. The added significance of this is that $15 \mathrm{mM}$ extracellular $\mathrm{KCl}$ produces a cell swelling and membrane depolarisation comparable to that observed following stimulation (Usher-Smith et al. 2006b) and thus, at physiological levels, the combination of swelling and depolarisation appears to maintain a constant T-SR distance. This tendency for isotonic cell swelling to increase T-SR distance was also observed at higher $\left[\mathrm{K}^{+}\right]_{\mathrm{e}}$ but here the effect was less pronounced. However, there must be a physical constraint on the minimal gap between the T-SR membranes related to the ion channels protruding from the surface of the T-SR membranes and the attachment of the membranes to the cytoskeleton of the myocytes (Franzini-Armstrong and Nunzi 1983). If the T-SR distance of $9.80 \pm$ $0.19 \mathrm{~nm}$ measured in $60 \mathrm{mM} \mathrm{K}_{2} \mathrm{SO}_{4}$ is close to this minimum separation, the absence of a significant difference between this and the distance in $60 \mathrm{mM} \mathrm{KCl}$ might then not reflect the full effect of the cell swelling.

In contrast, the T-tubule diameter after prior exposure to both concentrations of $\left[\mathrm{K}^{+}\right]_{\mathrm{e}}$ in the presence of $\mathrm{Cl}^{-}$was smaller than that observed in $\mathrm{SO}_{4}^{2-}$ solutions, showing that the additional effect of isosmotic cell swelling is to produce a decrease in T-tubule diameter. Previous TEM studies on frog sartorius muscles have shown that T-tubule diameter depends on both ionic strength and tonicity: decreasing ionic strength at constant tonicity leads to swelling of T-tubules whilst decreasing tonicity at constant ionic strength reduces T-tubule diameter (Freygang et al. 1967; Rapoport et al. 1969). This can be compared to the effects of exposure to simple hypotonic solutions, where both tonicity and ionic strength are reduced, where T-system volume then increases (Launikonis and Stephenson 2002; Martin et al. 2003). The present finding that isotonic cell swelling, which corresponds to a reduction in extracellular tonicity at constant ionic strength, decreases T-tubule diameter is therefore consistent with previous reports and confirms that cell swelling during exercise is not responsible for the associated increases in T-tubule diameter. Furthermore, in $15 \mathrm{mM}\left[\mathrm{K}^{+}\right]_{\mathrm{e}}$, when the swelling and depolarisation were comparable to that seen following stimulation (Usher-Smith et al. 2006b), there was in fact a small, but significant, reduction in T-tubule diameter.

The influence of intracellular acidification on triad anatomy at a constant extracellular $\mathrm{pH}$ was then investigated using a standard experimental protocol of $\mathrm{NH}_{4} \mathrm{Cl}$ addition and subsequent withdrawal which resulted in a $\mathrm{pH}_{\mathrm{i}}$ of approximately $6.74 \pm 0.10$ units (Fraser et al. 2005), close to the range 6.30-6.70 recorded in fatigued frog sartorius surface fibres (Renaud et al. 1986). This produced significant reductions in both T-SR distance and T-tubule diameter, although the latter change was small and unlikely to reflect a physiological effect. Although it is possible that these changes were the result of the $\mathrm{pH}$ gradient across the cell membrane during the acidification and fixation and not due to the intracellular $\mathrm{pH}$ itself, a similar gradient exists during the intracellular acidification following exercise and the observation that these conditions result in a decrease in both T-SR distance and T-tubule diameter makes it unlikely that they contribute to the increases in these parameters observed following stimulation. Additionally, the reduction in T-SR distance under these conditions was also close to that seen with $60 \mathrm{mM}\left[\mathrm{K}_{2} \mathrm{SO}_{4}\right]$, supporting the view that this represents the minimum separation between the two membranes.

The combined effect of this intracellular acidification and the accumulation of lactate which accompanies the production of $\mathrm{H}^{+}$in vivo was then investigated by exposing muscles to extracellular solutions containing lactate which produces changes in intracellular [lactate $\left.{ }^{-}\right]$and $\left[\mathrm{H}^{+}\right]$comparable to those following the stimulation protocol (Usher-Smith et al. 2006a). 
Comparing this to the effect of a decrease in $\mathrm{pH}_{\mathrm{i}}$ alone showed that the additional accumulation of intracellular lactate did not affect T-SR distance but did cause significant swelling of the T-tubule. This latter finding is in agreement with previous reports of T-tubule swelling and vacuolation in skeletal muscle fibres from frog and mouse exposed to lactate-Ringer (Lannergren et al., 2000) and is most likely explained by transport of lactate from the cell into the T-tubules where it attracts water. This is consistent with a recent quantitative study (Fraser et al. 2006) suggesting that this outward transport of lactate occurs because although most of the extracellular lactate at physiological $\mathrm{pH}$ is in the anionic form ( $\left.\mathrm{lac}^{-}\right)$, the cell membrane is relatively poorly permeable to $\mathrm{lac}^{-}$and furthermore the membrane potential ensures that lac is largely excluded from the cell. Thus, the majority of lactate entry is either in the more permeable protonated form (lacH) or as electroneutral $\mathrm{lac}^{-}-\mathrm{H}^{+}$transport (Juel and Halestrap 1999). However, the influx of lacH tends to increase the ratio of lacH to $\mathrm{lac}^{-}$within the cell, promoting dissociation of lacH into $\mathrm{lac}^{-}+\mathrm{H}^{+}$. The vast majority of these $\mathrm{H}^{+}$ions are then buffered by the various intracellular buffers, further promoting this dissociation of lacH. The relatively large buffering capacity of the cell ensures that the net result of these processes is a slow acidification of the cell and a faster accumulation of $\mathrm{lac}^{-}$. With $80 \mathrm{mM}$ extracellular lactate and membrane potential of $-85 \mathrm{mV}$, the equilibrium intracellular lac $^{-}$concentration is only approximately $2.5 \mathrm{mM}$, thus resulting in a rapid development of an outward electrochemical gradient for $\mathrm{lac}^{-}$. Its resulting efflux further promotes dissociation of intracellular lacH, thus maintaining the inward lacH (or $\mathrm{lac}^{-}+\mathrm{H}^{+}$) gradient despite the very small extracellular lacH concentration. This has been suggested to result in a cycling process with inward lacH movement, outward lac $^{-}$movement, and intracellular $\mathrm{H}^{+}$accumulation. If this outward $\mathrm{lac}^{-}$movement occurred into the T-system, this could result in an effective increase in local anion content, drawing cations and hence water into the T-tubules. One possible explanation for the observation that the T-tubule diameter under these conditions is greater than that seen following stimulation is that during stimulation lactate is continuously produced and transported into the T-tubules at rates that would result in roughly similar concentrations in the cytoplasm and the T-tubules producing a smaller gradient for water movement between the two compartments.

The anatomical results described here thus directly confirm earlier suggestions that repeated muscular contraction disrupts triad anatomy in skeletal muscle. By replicating various intracellular changes associated with activity in resting muscle they show that, of membrane depolarisation, isotonic cell swelling, intracellular acidification and lactate accumulation, only isotonic cell swelling increases T-SR distance and this is precisely balanced by the effect of membrane depolarisation in reducing T-SR distance, whilst membrane depolarisation and intracellular lactate likely contribute to the increases in T-tubule diameter. Although the present study does not provide detailed explanations for all these findings, it does provide clear cut evidence that both T-SR distance and T-tubule diameter are affected by a range of cellular conditions known to be associated with exercise. These findings contrast with recent reports that the triads have robust structural properties that remain stable despite a single mechanical stress: the width of the junctional gap between the T-tubule and the SR terminal cisternae, as well as the orientation of the triads, remains constant despite stretch of the sarcomere length to over $5 \mu \mathrm{m}$ (Takekura et al. 1996). It is thus particularly surprising that they are so sensitive to membrane potential, a parameter that would not be expected intrinsically to alter cellular ultrastructure.

Acknowledgements C.L.-H. Huang thanks the Medical Research Council, the Wellcome Trust and the British Heart Foundation for generous support. J.A. Fraser thanks Gonville and Caius College for a Research Fellowship. J.N. Skepper thanks the Wellcome Trust and J.A. Usher-Smith thanks Astra Zeneca and acknowledges additional support from the James Baird Fund.

\section{References}

Adrian RH (1956) The effect of internal and external potassium concentration on the membrane potential of frog muscle. J Physiol 133:631-658

Allen DG, Lee JA, Westerblad H (1989) Intracellular calcium and tension during fatigue in isolated single muscle fibres from Xenopus laevis. J Physiol 415:433-458

Balnave CD, Allen DG (1995) Intracellular calcium and force in single mouse muscle fibres following repeated contraction with stretch. J Physiol 488:23-36

Bangsbo J, Gollnick PD, Graham TE, Juel C, Kiens B, Mizuno M, Saltin B (1990) Anaerobic energy production and $\mathrm{O}_{2}$ deficit-debt relationship during exhaustive exercise in humans. J Physiol 422:539-559

Blinks JR (1965) Influence of osmotic strength on cross-section and volume of isolated single muscle fibres. J Physiol $177: 42-57$

Boron WF, De Weer P (1976) Intracellular $\mathrm{pH}$ transients in squid giant axons caused by $\mathrm{CO}_{2}, \mathrm{NH}_{3}$, and metabolic inhibitors. J Gen Physiol 67:91-112

Boyle PJ, Conway EJ (1941) Potassium accumulation in muscle and associated changes. J Physiol 100:1-63

Bressler BH, Matsuba K (1991) Tension and instantaneous stiffness of single muscle fibres immersed in ringer solution of decreased tonicity. Biophys J 59:1002-1006 
Bruton JD, Szentesi P, Lannergren J, Westerblad H, Kovacs L, Csernoch L (2000) Frog skeletal muscle fibres recovering from fatigue have reduced charge movement. J Muscle Res Cell Motil 21:621-628

Chawla S, Skepper JN, Hockaday AR, Huang CL-H (2001) Calcium waves induced by hypertonic solutions in intact frog skeletal muscle fibres. J Physiol 536:351-359

Dulhunty A (1982) Effect of chloride withdrawal on the geometry of the T-tubules in amphibian and mammalian muscle. J Membr Biol 67:81-90

Eisenberg BR, Gilai A (1979) Structural changes in single muscle fibres after stimulation at a low frequency. J Gen Physiol 74:1-16

Franzini-Armstrong C, Nunzi G (1983) Junctional feet and particles in the triads of a fast-twitch muscle fibre. J Muscle Res Cell Motil 4:233-252

Franzini-Armstrong C, Protasi F (1997) Ryanodine receptors of striated muscles: a complex channel capable of multiple interactions. Physiol Rev 77:699-729

Fraser JA, Huang CL-H (2004) A quantitative analysis of cell volume and resting potential determination and regulation in excitable cells. J Physiol 559:459-478

Fraser JA, Middlebrook CE, Usher-Smith JA, Schwiening CJ, Huang CL-H (2005) The effect of intracellular acidification on the relationship between cell volume and membrane potential in amphibian skeletal muscle. J Physiol 563:745-764

Fraser JA, Usher-Smith JA, Huang CL-H (2006) Chargedifference modeling of the influence of intracellular lactate and $\mathrm{H}^{+}$on cell volume in skeletal muscle. Appendix in: the influence of intracellular lactate and $\mathrm{H}^{+}$on cell volume in amphibian skeletal muscle. J Physiol 573:812-818

Freygang WH, Goldstein DA, Hellam DC, Peachey LD (1964) The relation between the late after-potential and the size of the transverse tubular system of frog muscle. J Gen Physiol 48:235-263

Freygang WH, Rapoport SI, Peachey LD (1967) Some relations between changes in the linear electrical properties of striated muscle fibres and changes in ultrastructure. J Gen Physiol 50:2437-2458

Frias JA, Cadefau JA, Prats C, Moran M, Megias A, Cusso R (2004) Disturbances of the sarcoplasmic reticulum and transverse tubular system in 24-h electrostimulated fasttwitch skeletal muscle. Biochim Biophys Acta 1668:64-74

Gonzalez-Serratos H, Somlyo AV, McClellan G, Shuman H, Borrero LM, Somlyo AP (1978) Composition of vacuoles and sarcoplasmic reticulum in fatigued muscle: electron probe analysis. Proc Natl Acad Sci USA 75:1329-1333

Huang CL (1993) Charge inactivation in the membrane of intact frog striated muscle fibers. J Physiol 468:107-124

Huang CL-H (1998) The influence of perchlorate ions on complex charging transients in amphibian striated muscle. J Physiol 506:699-714

Ingalls CP, Warren GL, Williams JH, Ward CW, Armstrong RB (1998) E-C coupling failure in mouse EDL muscle after in vivo eccentric contractions. J Appl Physiol 85:58-67

Juel C (1986) Potassium and sodium shifts during in vitro isometric muscle contraction, and the time course of the iongradient recovery. Pflugers Arch 406:458-463

Juel C (1988) Muscle $\mathrm{pH}$ regulation: role of training. Acta Physiol Scand 162:359-366

Juel C, Halestrap AP (1999) Lactate transport in skeletal muscle-role and regulation of the monocarboxylate transporter. J Physiol 517:633-642

Krause U, Wegener G (1996) Exercise and recovery in frog muscle: metabolism of $\mathrm{PCr}$, adenine nucleotides, and related compounds. Am J Physiol 270:R821-R829
Lamb GD, Junankar PR, Stephenson DG (1995) Raised intracellular $\left[\mathrm{Ca}^{2+}\right]$ abolishes excitation-contraction coupling in skeletal muscle fibres of rat and toad. J Physiol 489.2:349 362

Lannergren J (1990) Volume changes of isolated Xenopus muscle fibres associated with repeated tetanic contractions. J Physiol 420:116P

Lannergren J, Bruton JD, Westerblad H (2000) Vacuole formation in fatigued skeletal muscle fibres from frog and mouse: effects of extracellular lactate. J Physiol 526:597-611

Lannergren J, Westerblad H (1987) Action potential fatigue in single skeletal muscle fibres of Xenopus. Acta Physiol Scand 129:311-318

Lannergren J, Westerblad H, Flock B (1990) Transient appearance of vacuoles in fatigued Xenopus muscle fibres. Acta Physiol Scand 140:437-445

Launikonis BS, Stephenson DG (2002) Tubular system volume changes in twitch fibres from toad and rat skeletal muscle assessed by confocal microscopy. J Physiol 538:607-618

Lindinger MI, Sjogaard G (1991) Potassium regulation during exercise and recovery. Sports Med 11:382-401

Martin CA, Petousi N, Chawla S, Hockaday AR, Burgess AJ, Fraser JA, Huang CL-H, Skepper JN (2003) The effect of extracellular tonicity on the anatomy of triad complexes in amphibian skeletal muscle. J Muscle Res Cell Motil 24:407-415

Mason MJ, Thomas RC (1988) A microelectrode study of the mechanisms of L-Lactate entry into and release from frog sartorius muscle. J Physiol 400:459-479

Nakai J, Dirksen RT, Nguyen HT, Pessah IN, Beam KG, Allen PD (1996) Enhanced dihydropyridine receptor channel activity in the presence of ryanodine receptor. Nature 380:72-75

Peracchia C, Mittler BS (1972) Fixation by means of glutaraldehyde-hydrogen peroxide reaction products. J Cell Biol 53(1):234-238

Putnam RW, Roos A, Wilding TJ (1986) Properties of the intracellular $\mathrm{pH}$-regulating systems of frog skeletal muscle. J Physiol 381:205-219

Rapoport SI, Peachey LD, Goldstein DA (1969) Swelling of the transverse tubular system in frog sartorius. J Gen Physiol 54:166-177

Rapp G, Ashley CC, Bagni MA, Griffiths PJ, Cecchi G (1998) Volume changes of the myosin lattice resulting from repetitive stimulation of single muscle fibres. Biophys J 75:2984-2995

Renaud JM, Allard Y, Mainwood GW (1986) Is the change in intracellular $\mathrm{pH}$ during fatigue large enough to be the main cause of fatigue? Can J Physiol Pharmacol 64:764-767

Sjogaard G (1983) Electrolytes in slow and fast muscle fibres of humans at rest and with dynamic exercise. Am J Physiol Regul Integr Comp Physiol 245:R25-R31

Sjogaard G, Adams RP, Saltin B (1985) Water and ion shifts in skeletal muscle of humans with intense dynamic knee extension. Am J Physiol 248:R190-R196

Sjoholm H, Sahlin K, Edstrom L, Hultman E (1983) Quantitative estimation of anaerobic and oxidative energy metabolism and contraction characteristics in intact human skeletal muscle in response to electrical stimulation. Clin Physiol 3:227-239

Somlyo AP, Somlyo AV, Shuman H, Sloane B, Scarpa A (1978) Electron probe analysis of the sarcoplasmic reticulum and mitochondria in muscle. Microsc Acta Suppl 2:79-91

Sullivan MJ, Saltin B, Negro-Vilar R, Duscha BD, Charles HC (1994) Skeletal muscle $\mathrm{pH}$ assessed by biochemical and 31PMRS methods during exercise and recovery in men. J Appl Physiol 77:2194-2200 
Takekura H, Fujinami N, Nishizawa T, Ogasawara H, Kasuga N (2001) Eccentric exercise-induced morphological changes in the membrane systems involved in excitation-contraction coupling in rat skeletal muscle. J Physiol 533:571-583

Takekura H, Kasuga N, Yoshioka T (1996) Influences of sarcomere length and selective elimination of myosin filaments on the localization and orientation of triads in rat skeletal muscle. J Muscle Res Cell Motil 17:235-242

Usher-Smith JA, Fraser JA, Bailey PSJ, Griffin JL, Huang CL-H (2006a) The influence of intracellular lactate and $\mathrm{H}^{+}$on cell volume in amphibian skeletal muscle. J Physiol 573:799-818

Usher-Smith JA, Skepper JN, Fraser JA, Huang CL-H (2006b) Effect of repetitive stimulation on cell volume and its relationship to membrane potential in amphibian skeletal muscle. Pflugers Arch 452:231-239

Vaughan-Jones RD (1982) Chloride activity and its control in skeletal and cardiac muscle. Philos Trans R Soc Lond B Biol Sci 299:537-548

Vaughan-Jones RD, Wu ML (1990) pH dependence of intrinsic $\mathrm{H}^{+}$buffering power in the sheep cardiac Purkinje fibre. $\mathrm{J}$ Physiol 425:429-448
Verburg E, Dutka T, Lamb G (2006) Long-lasting muscle fatigue: partial disruption of excitation-contraction coupling by elevated cytosolic $\mathrm{Ca}^{2+}$ concentration during contractions. Am J Physiol Cell Physiol 290:C1199-C1208

Verburg E, Murphy RM, Stephenson DG, Lamb G (2005) Disruption of excitation-contraction coupling and titin by endogenous $\mathrm{Ca}^{2+}$-activated proteases in toad muscle fibres. $\mathbf{J}$ Physiol 564:775-790

Warren GL, Lowe DA, Hayes DA, Karwoski CJ, Prior BM, Armstrong RB (1993) Excitation failure in eccentric contraction-induced injury of mouse soleus muscle. J Physiol 468:487-499

Westerblad H, Lannergren J (1986) Force and membrane potential during and after fatiguing, intermittent tetanic stimulation of single Xenopus muscle fibres. Acta Physiol Scand 128:369-378

Williams JH (2004) Effects of fatigue on depolarisation- and caffeine-induced contractures of skinned fibres. Acta Physiol Scand 180:265-269 